\title{
Virilisation in a menopausal woman with a previous kidney transplant
}

\author{
TM Fung *, WC Wong, KW Chan, KS Fung
}

Hong Kong Med J 2016;22:623.e3-4

DOI: 10.12809/hkmj164901

A 53-year-old woman, menopausal for 4 years and with a previous kidney transplant presented with a 3 -year history of excessive facial and body hair that required daily shaving in January 2008 (Fig 1). She had had no postmenopausal bleeding or gynaecological disease. She was prescribed immunosuppressants and corticosteroids but no hormones. There was no acne or hoarseness of voice. Examination revealed frontal balding and excessive hair over her chin, both shins, and lower abdomen with mild clitoromegaly. Serum testosterone was $19 \mathrm{nmol} / \mathrm{L}$ (reference range, 0.35-2.65 nmol/L); 17-hydroxyprogesterone (17OHP) and dehydroepiandrosterone sulfate (DHEAS) levels were normal. Adrenocorticotropic hormone and cortisol levels were normal after overnight dexamethasone suppression test. Her folliclestimulating hormone, luteinising hormone, thyroidstimulating hormone, and prolactin levels were also normal. Serum oestradiol was in the premenopausal range $(298 \mathrm{nmol} / \mathrm{L})$. Transvaginal ultrasound showed a normal uterus with endometrial thickness of $5 \mathrm{~mm}$ and no adnexal masses.

Questions:

1. What are the differential diagnoses?

2. What further investigations are helpful?

3. How should the patient be managed?

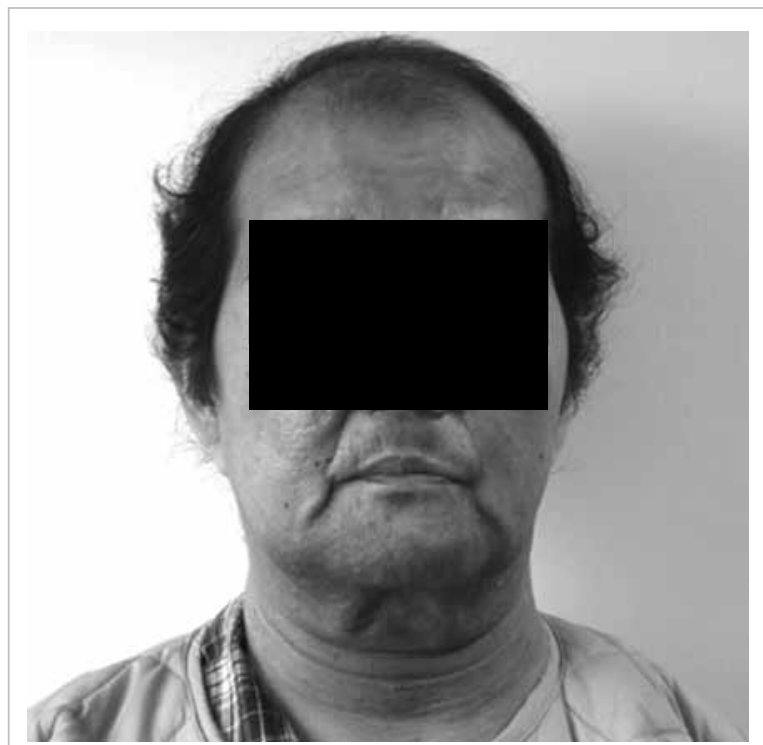

FIG I. Facial features of the patient with frontal balding and prominent facial hair requiring regular shaving

\section{Answers:}

1. Androgen-secreting tumours of the ovary or adrenal gland.

Hirsutism involves excessive terminal hair growth in a masculine distribution in women. It can occur as a side-effect of immunosuppressants, eg cyclosporin with gingival hyperplasia and hirsutism. Nonetheless virilisation is uncommon. Cyclosporin should be changed to tacrolimus when hirsutism occurs.

Virilisation (development of male characteristics in women) occurs in less than $1 \%$ of patients with hirsutism. When it occurs (temporal hair recession and clitoromegaly in this patient) androgen-secreting tumours of the ovaries or adrenals should be suspected, particularly when onset is sudden with rapid progression.

2. Patients with virilisation should have serum testosterone, 17-OHP, and DHEAS checked. Serum testosterone level of $>200 \mathrm{ng} / \mathrm{dL}$ (ie 6.94 $\mathrm{nmol} / \mathrm{L}$ or 3 times normal) and/or DHEAS level of $>700 \mu \mathrm{g} / \mathrm{dL}$ (ie $24.3 \mathrm{nmol} / \mathrm{L}$ ) are indicative of virilising tumours. ${ }^{1,2}$ Computed tomography (CT) of the adrenals and pelvis should be considered. Ultrasonography of the pelvis may be difficult and not diagnostic in menopausal women because the ovaries are small and steroid-secreting tumours

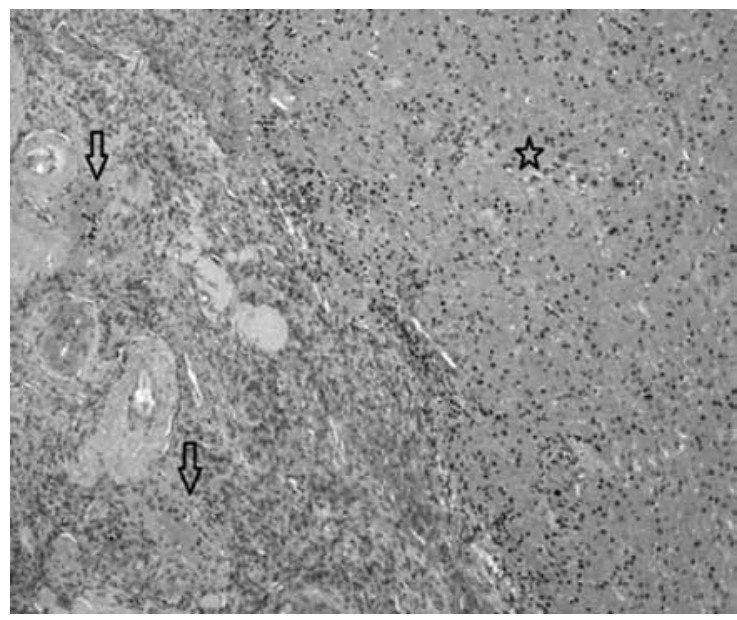

FIG 2. Histology of the right ovary showing stromal luteoma comprising polygonal luteinised cells with abundant eosinophilic cytoplasm (star), surrounded by ovarian stroma with clusters of luteinised cells (arrows) that constitute stromal hyperthecosis (H\&E; original magnification, $x$ 100) 
can be $<1 \mathrm{~cm}$ in diameter. ${ }^{3}$ In this patient, normal levels of DHEAS and 17-OHP made adrenal tumour and congenital adrenal hyperplasia unlikely. Ovarian virilising tumours have to be suspected. Preoperative CT pelvis showed a 1-cm cyst in her right ovary.

3. Endometrial aspirate was performed, there was no hyperplasia or malignancy. She underwent laparotomy and bilateral salpingo-oophorectomy. There was a $1-\mathrm{cm}$ yellowish tumour in the right ovary. The left ovary appeared normal. Hysterectomy was not done as the uterus was densely adhered to the bowel (history of peritoneal dialysis). Histology confirmed stromal luteoma and hyperthecosis in both ovaries without malignancy (Fig 2). After surgery, her testosterone level normalised. Hair re-grew over her frontal region and her body hair reduced.

Ovarian steroid cell tumours account for $0.1 \%$ to $0.2 \%$ of all ovarian tumours, and are composed of cells resembling steroid-secreting cells. ${ }^{4}$ Steroid cell tumours of small size and confined to the ovarian stroma are conventionally designated stromal luteomas and are usually associated with stromal hyperthecosis in adjacent stroma. They can have oestrogenic and/or androgenic manifestations with postmenopausal bleeding or virilisation, and are associated with endometrial hyperplasia or carcinoma. ${ }^{5}$ Hysterectomy and bilateral salpingo- oophorectomy is advised as some of these tumours may have malignant potential.

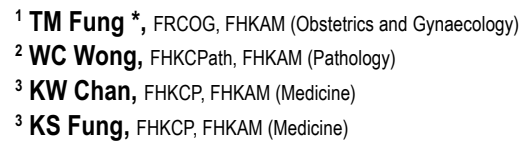

${ }^{1}$ Department of Obstetrics and Gynaecology, Princess Margaret Hospital, Laichikok, Hong Kong

2 Department of Clinical Pathology, Pamela Youde Nethersole Eastern Hospital, Chai Wan, Hong Kong

${ }^{3}$ Department of Medicine and Geriatrics, Princess Margaret Hospital, Laichikok, Hong Kong

* Corresponding author: fungtm@ha.org.hk

\section{References}

1. Somani N, Harrison S, Bergfeld WF. The clinical evaluation of hirsutism. Dermatol Ther 2008;21:376-91.

2. Hunter MH, Carek PJ. Evaluation and treatment of women with hirsutism. Am Fam Physician 2003;67:2565-72.

3. Outwater EK, Wagner BJ, Mannion C, McLarney JK, Kim B. Sex cord-stromal and steroid cell tumors of the ovary. Radiographics 1998;18:1523-46.

4. Hayes MC, Scully RE. Stromal luteoma of the ovary: a clinicopathological analysis of 25 cases. Int J Gynecol Pathol 1987;6:313-21.

5. Yamada S, Tanimoto A, Wang KY, Shimajiri S, Sasaguri Y. Stromal luteoma and nodular hyperthecosis of the bilateral ovaries associated with atypical endometrial hyperplasia of the uterus. Pathol Int 2009;59:831-3. 